\title{
ARTICLE
}

\section{Radioactivity evaluation for Main Steam Line and Suppression Chamber of small type BWR}

\author{
Ken-ichi Tanaka* and Hideaki Ichige \\ The Japan Atomic Power Company, 1-1 Kanda-Mitoshiro-cho Chiyoda-ku Tokyo, 101-0053, Japan
}

\begin{abstract}
We, The Japan Atomic Power Company, have already started preparatory tasks for decommissioning of Tsuruga Nuclear Power Station unit 1 (TS-1), a small type BWR. Radiological characterization of the plant is one of important task of these tasks. We have performed radioactivity distribution calculation as radiological characterization around the reactor in Primary Containment Vessel (PCV) and in Biological Shielding Wall (BSW) and have obtained reliable information. But we needed more information on radioactivity distribution in TS-1 Reactor Building to plan rational decommissioning planning. In this work, we extended calculation areas to around Main Steam Line (MS), around Feed Water Line (FW) and around Suppression Chamber (S/C), where we needed special treatments. Local neutron transport phenomena, such as neutron streaming through MS, FW and Vent Tube, is observed there. To simulate such neutron transport phenomena well, we performed the calculations using three-dimensional neutron transport calculation code named TORT, applying "Coupling Calculation" technique. Calculations showed that all materials in these areas could be treated as non-radioactive. In order to verify reliability of calculations, we also performed radioactivity measurements. And Comparison between calculations and measurements proved that calculations had quantitative reliability.
\end{abstract}

Keywords: decommissioning; BWR; radioactivity distribution; non radioactive (NR); neutron flux distribu -tion; neutron irradiation; TORT; ORIGEN-S; activation foil

\section{Introduction}

Radiological characterization for a nuclear power plant is an important task of preparatory tasks for decommissioning and is performed at the first step of the tasks. The preparatory tasks are radiological characterization, dismantlement planning, dismantle -ment cost estimation, a disposal planning, disposal cost estimation, safety assessment for decommissioning and so on. We perform radioactivity distribution calculations and radioactivity measurements in radiological characterization. The calculations must be verified with the measurements. And radiological characterization will give information on radioactivity distribution in the plant and on amount of waste from decommissioning. Reliable information from the radiological characterization makes other tasks rational.

One of the most important information from radiological characterization is radioactivity level identification for materials in the plant. We identify the radioactivity level by assessing the radioactivity distribution. Dismantlement planning needs the information because a selection of dismantlement method depends on radioactivity level of materials. And dismantling cost and disposal cost of waste materials from a decommissioning also depends on the level. The information is indispensable to a rational dismantlement

*Corresponding author. Email: kenichi-tanaka@japc.co.jp planning, a rational disposal planning and optimized cost estimations.

When performing the radioactivity level identification, we identify non-radioactive materials. According to the safety guide report for radioactive waste treatment by regulatory body in Japan, materials, which irradiated by neutron less than $6.25 \mu \mathrm{Sv} / \mathrm{h}$, can be treated as non-radioactive. We apply this guideline to an identification of non-radioactive material.

We call a boundary line, at which materials in the plant are distinguished between radioactive or non-radioactive, "NR boundary (Non-radioactive boundary)". NR boundary is also estimated in performing radioactivity distribution calculation. Materials, which are outside of NR boundary, can be treated as non-radioactive materials.

We have already started preparatory tasks for decommissioning of Tsuruga Nuclear Power Plant Unit 1 (TS-1), a small type BWR. We have started radiological characterization of TS-1 with radioactivity distribution calculation around the reactor in Primary Containment Vessel (PCV) and in Biological Shielding Wall (BSW). The calculation has indicated that NR boundary is in BSW. The calculation has been verified with radioactivity measurements and its reliability was confirmed [1].

Although the radioactivity distribution calculation 
around the reactor has been performed, two areas where we needed special treatments were still remained. One area was around Main Steam Line (MS) and Feed Water Line (FW). Another was around Vent Tubes. MS and FW are located in "MS-tunnel Room" and Vent Tubes connect Primary Containment Vessel (PCV) and Suppression Chamber Room ("S/C-Room") as shown in Figure 1. MS-tunnel Room and S/C-Room are in TS-1 Reactor Building. MS, FW and Vent Tubes go through BSW. Local neutron transport phenomena, neutron streaming through MS, FW and Vent Tubes and irradiating materials around them, are observed in these areas. In this work, we performed radioactivity distribution calculations and identified radioactivity level of materials in MS-tunnel Room and in S/C-Room. The calculations were verified with radioactivity measurements in these areas. We also estimated NR boundary in these areas.

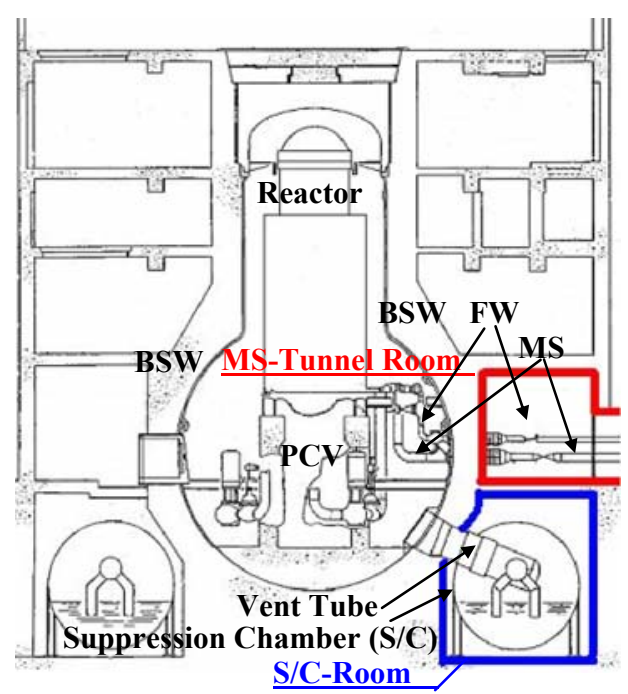

Figure 1. Cross section view of TS-1 Reactor Building.

\section{Measurements and calculation}

\subsection{Radioactivity measurements}

In order to verify the calculations, we measured radioactivity generated by neutron flux irradiation using activation foil sets at 15 locations in MS-tunnel Room and in S/C-Room, where the local neutron transport phenomena can be observed. Nickel (Ni) foil and Gold (Au) foil were used for the activation foil set. We used $\mathrm{Ni}$ foil to measure radioactivity generated by neutron flux irradiation in fast energy range. To measure radioactivity, which was activated by epi-thermal neutron flux and thermal neutron flux, we used $\mathrm{Au}$ foils. We located 10 foil sets in MS-tunnel Room and other 5 foil sets were in S/C-Room. These foils were irradiated during one operation cycle, which is about 13 months. After the irradiation, we used Germanium Detector to measure the radioactivity of foils and its detecting time was 10,000 seconds.

\subsection{Calculations}

Radioactivity distribution calculation is composed of three kinds of calculations; these are neutron flux distribution calculation, dose distribution calculation and activation calculation. First, we performed neutron flux distribution calculations in MS-tunnel Room and in S/CRoom. Accessing the neutron flux distributions, we calculated dose distributions in these areas and calculated radioactivity at activation foil set locations.

\subsubsection{Neutron flux calculation}

In order to simulate the local neutron transport phenomena well, we performed neutron flux distribution calculations in MS-tunnel Room and in S/C-Room using three-dimensional (3D) neutron transport calculation code named TORT [2] with MATX-J33 [3] neutron cross section library. In these calculations, neutron source data were given as "TORT boundary source input data" [2], which generated from the previous calculation [1] using VISA code and TORSED code [2]. To generate neutron source data from a previous calculation using these codes is called "Coupling Calculation" [2]. In the previous work, neutron flux distribution calculation was performed in two-dimensional (2D) cylindrical coordinate system. Applying the Coupling Calculation technique, we converted the neutron flux distribution in 2D cylindrical coordinate system into the neutron source data in 3D rectangular coordinate system. 3D calculation code applying the technique makes it possible to simulate neutron flux distributions well in MS-tunnel Room and in S/C-Room.

\subsubsection{Dose distribution calculation}

To obtain dose distribution in MS-tunnel Room and in S/C-Room, we converted these neutron flux distributions to dose distributions with "Neutron Flux-Effective Dose Conversion Coefficient" [4]. The conversion gave $3 \mathrm{D}$ dose distributions. To grasp the characteristics of the distributions, we draw dose distribution contour maps on arbitrary planes in the 3D distribution, where local neutron transport phenomena can be observed: around MS, FW and Vent Tube. And we estimated NR boundaries in MS-tunnel Room and $\mathrm{S} / \mathrm{C}$-Room assessing these contour maps.

\subsubsection{Activation calculation}

Activation calculation for $\mathrm{Ni}$ foils and $\mathrm{Au}$ foils at 15 activation foil set locations were performed using ORIGEN-S [5]. We picked up neutron flux at these locations in the neutron flux distributions and input them to ORIGEN-S as "ORIGEN-S neutron flux input data". Operation history during the operation cycle was given as "ORIGEN-S irradiation period input data" [5]. Calculated radioactivities of $\mathrm{Ni}$ and of $\mathrm{Au}$ were compared with measured ones to verify reliability of neutron flux distribution calculations. 


\section{Results}

\subsection{Radioactivity measurements}

Measured radioactivity at 15 locations are shown in Table 1. We measured ${ }^{58} \mathrm{Co}$ radioactivity generated in $\mathrm{Ni}$ foil and ${ }^{198} \mathrm{Au}$ radioactivity generated in $\mathrm{Au}$ foil by neutron flux irradiation. Radioactivity in Ni foils were not detected (ND) at any 15 locations. And at location 10 , neither radioactivity in $\mathrm{Ni}$ foil nor radioactivity in $\mathrm{Au}$ foil was detected.

\subsection{Dose distribution and NR boundary estimation}

Dose distribution contour maps on $\mathrm{X}-\mathrm{Z}$ plane at MS center and at FW center in MS-tunnel Room are shown in Figure 2. That on $\mathrm{X}-\mathrm{Z}$ plane at Vent Tube center in
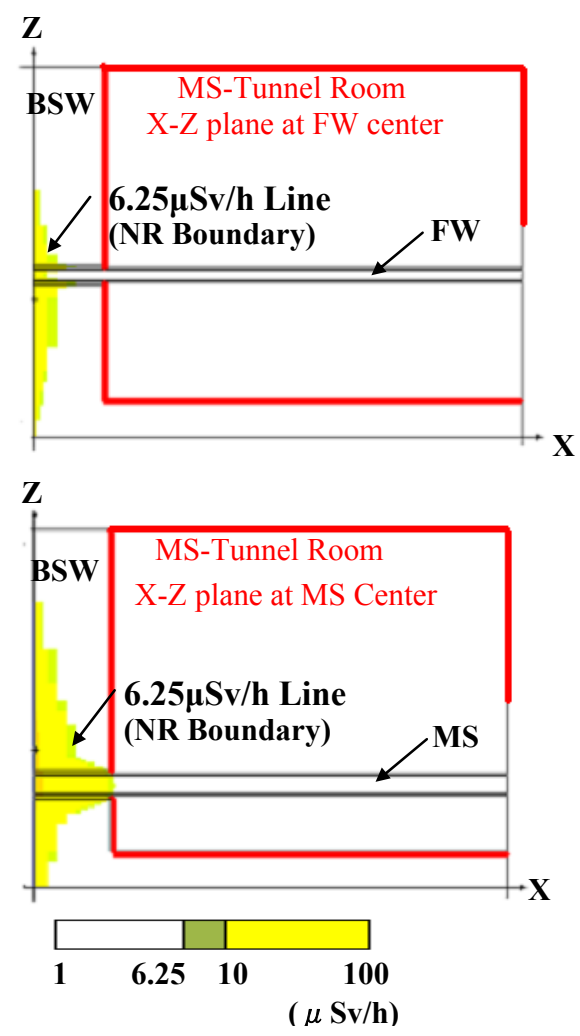

Figure 2. Dose distribution in MS-tunnel Room.

S/C-Room is shown in Figure 3. Red line and blue line in these figures indicate the same ranges, which are shown in Figure 1, respectively.

We drew dose distribution contour maps on $\mathrm{X}-\mathrm{Z}$ plane at MS center, at FW center and at Vent Tube center because highest dose levels around MS, around FW and around Vent Tube were observed there.

Area where dose is less than $6.25 \mu \mathrm{Sv} / \mathrm{h}$ is painted in white on the maps. As shown in these figures, NR boundaries are located in BSW and all materials in MS-tunnel Room and in S/C-Room can be treated as non-radioactive.
S/C-Room
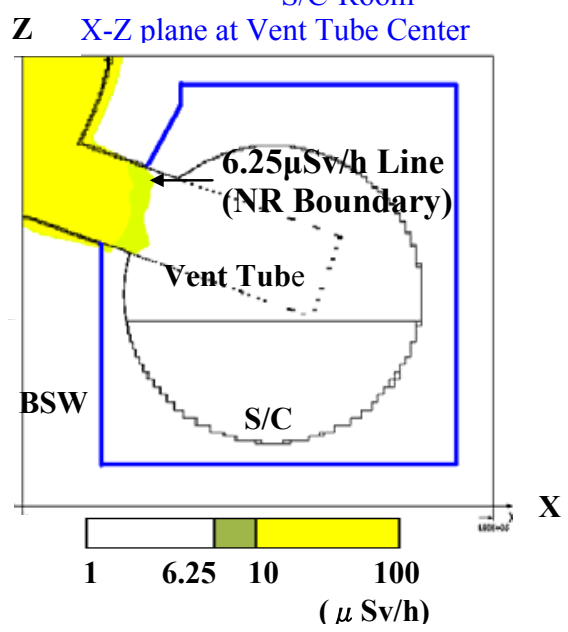

Figure 3. Dose distribution in S/C-Room.

\subsection{Verifications}

Measured radioactivity, calculated radioactivity and comparison between both ones $(\mathrm{C} / \mathrm{M})$ at 15 locations are shown in Table 1.

Table 1. Measured radioactivity, calculated radioactivity and $\mathrm{C} / \mathrm{M}$ in MS-Tunnel Room and in S/C-Room of activation Foils.

\begin{tabular}{|c|c|c|c|c|c|}
\hline \multirow{2}{*}{ No } & \multirow{2}{*}{$\begin{array}{l}\text { Foil } \\
\text { type }\end{array}$} & \multicolumn{2}{|c|}{$\begin{array}{c}\text { Measured } \\
\text { radioactivity }\end{array}$} & \multicolumn{2}{|c|}{$\begin{array}{l}\text { Calculated } \\
\text { radioactivity }\end{array}$} \\
\hline & & Isotope & $\begin{array}{c}\text { Radioactivity } \\
\text { (Bq) }\end{array}$ & $\begin{array}{c}\text { Radioactivity } \\
\text { (Bq) }\end{array}$ & $\mathrm{C} / \mathrm{M}$ \\
\hline \multirow{2}{*}{1} & $\mathrm{Au}$ & ${ }^{198} \mathrm{Au}$ & $4.06 \mathrm{E}+00$ & $4.43 \mathrm{E}+00$ & 1.09 \\
\hline & $\mathrm{Ni}$ & ${ }^{58} \mathrm{Co}$ & ND & $2.50 \mathrm{E}-04$ & - \\
\hline \multirow[b]{2}{*}{2} & $\mathrm{Au}$ & ${ }^{198} \mathrm{Au}$ & $2.38 \mathrm{E}+00$ & $7.02 \mathrm{E}+00$ & 2.96 \\
\hline & $\mathrm{Ni}$ & ${ }^{58} \mathrm{Co}$ & ND & 4.34E-04 & - \\
\hline \multirow{2}{*}{3} & $\mathrm{Au}$ & ${ }^{198} \mathrm{Au}$ & $1.42 \mathrm{E}+00$ & $5.85 \mathrm{E}+00$ & 4.11 \\
\hline & $\mathrm{Ni}$ & ${ }^{58} \mathrm{Co}$ & ND & $5.47 \mathrm{E}-04$ & - \\
\hline \multirow{2}{*}{4} & $\mathrm{Au}$ & ${ }^{198} \mathrm{Au}$ & $2.33 \mathrm{E}+00$ & $9.00 \mathrm{E}+00$ & 3.86 \\
\hline & $\mathrm{Ni}$ & ${ }^{58} \mathrm{Co}$ & ND & $8.40 \mathrm{E}-04$ & - \\
\hline \multirow{2}{*}{5} & $\mathrm{Au}$ & ${ }^{198} \mathrm{Au}$ & $2.26 \mathrm{E}+00$ & $1.55 \mathrm{E}+00$ & 0.69 \\
\hline & $\mathrm{Ni}$ & ${ }^{58} \mathrm{Co}$ & ND & $1.04 \mathrm{E}-04$ & - \\
\hline \multirow{2}{*}{6} & $\mathrm{Au}$ & ${ }^{198} \mathrm{Au}$ & $2.28 \mathrm{E}+00$ & $8.66 \mathrm{E}-01$ & 0.38 \\
\hline & $\mathrm{Ni}$ & ${ }^{58} \mathrm{Co}$ & ND & $3.66 \mathrm{E}-05$ & - \\
\hline \multirow{2}{*}{7} & $\mathrm{Au}$ & ${ }^{198} \mathrm{Au}$ & $2.11 \mathrm{E}+00$ & $1.23 \mathrm{E}+00$ & 0.58 \\
\hline & $\mathrm{Ni}$ & ${ }^{58} \mathrm{Co}$ & ND & $9.14 \mathrm{E}-05$ & -- \\
\hline \multirow{2}{*}{8} & $\mathrm{Au}$ & ${ }^{198} \mathrm{Au}$ & $1.77 \mathrm{E}+00$ & $1.22 \mathrm{E}+00$ & 0.69 \\
\hline & $\mathrm{Ni}$ & ${ }^{58} \mathrm{Co}$ & ND & $9.18 \mathrm{E}-05$ & - \\
\hline \multirow{2}{*}{9} & $\mathrm{Au}$ & ${ }^{198} \mathrm{Au}$ & $6.50 \mathrm{E}-01$ & $1.23 \mathrm{E}+00$ & 1.90 \\
\hline & $\mathrm{Ni}$ & ${ }^{58} \mathrm{Co}$ & ND & $8.96 \mathrm{E}-05$ & - \\
\hline \multirow{2}{*}{10} & $\mathrm{Au}$ & ${ }^{198} \mathrm{Au}$ & ND & - & - \\
\hline & $\mathrm{Ni}$ & ${ }^{58} \mathrm{Co}$ & ND & - & - \\
\hline \multirow{2}{*}{11} & $\mathrm{Au}$ & ${ }^{198} \mathrm{Au}$ & $2.54 \mathrm{E}+00$ & $4.54 \mathrm{E}+00$ & 1.79 \\
\hline & $\mathrm{Ni}$ & ${ }^{58} \mathrm{Co}$ & ND & $8.60 \mathrm{E}-05$ & - \\
\hline \multirow{2}{*}{12} & $\mathrm{Au}$ & ${ }^{198} \mathrm{Au}$ & $5.27 \mathrm{E}+00$ & $6.51 \mathrm{E}+00$ & 1.24 \\
\hline & $\mathrm{Ni}$ & ${ }^{58} \mathrm{Co}$ & ND & $4.76 \mathrm{E}-04$ & - \\
\hline \multirow{2}{*}{13} & $\mathrm{Au}$ & ${ }^{198} \mathrm{Au}$ & $1.20 \mathrm{E}+02$ & $7.82 \mathrm{E}+01$ & 0.65 \\
\hline & $\mathrm{Ni}$ & ${ }^{58} \mathrm{Co}$ & ND & $1.57 \mathrm{E}-02$ & - \\
\hline \multirow{2}{*}{14} & $\mathrm{Au}$ & ${ }^{198} \mathrm{Au}$ & $2.51 \mathrm{E}-01$ & $1.67 \mathrm{E}-01$ & 0.67 \\
\hline & $\mathrm{Ni}$ & ${ }^{58} \mathrm{Co}$ & ND & $1.65 \mathrm{E}-06$ & - \\
\hline \multirow{2}{*}{15} & $\mathrm{Au}$ & ${ }^{198} \mathrm{Au}$ & $5.43 \mathrm{E}-01$ & $1.64 \mathrm{E}-01$ & 0.30 \\
\hline & $\mathrm{Ni}$ & ${ }^{58} \mathrm{Co}$ & ND & $1.49 \mathrm{E}-06$ & - \\
\hline
\end{tabular}


All $\mathrm{C} / \mathrm{M}$ values, which are calculated value divided by measured value, are less than one order magnitude. It shows that the calculations have quantitative reliability [6]. This verification proved that the dose distribution calculations and the estimations of NR boundary in MS-tunnel Room and in S/C-Room are reliable.

\section{Summary and conclusions}

We performed radioactivity distribution calculations in MS-tunnel Room and in S/C-Room. Assessing the dose distribution calculations, we estimated NR boundary in MS-tunnel Room and in $\mathrm{S} / \mathrm{C}$-Room. The estimations proved that NR boundaries are located in BSW and that all materials in these areas are non-radioactive. $\mathrm{C} / \mathrm{M}$ values at all activation foil locations being less than one order magnitude proved that the calculations have quantitative reliability. We obtained reliable information on radioactivity distribution in MS-tunnel Room and in S/C-Room. Referencing both the information and the previous information, we will be able to plan a rational Reactor Building dismantling plan and to optimize cost estimations.

We applied Coupling Calculation technique to the neutron distribution calculations. By considering the theoretical background of the technique, we could perform neutron flux distribution calculations reliable. And we proved that this technique is effective when we need to extend a range of radioactivity distribution calculation.

\section{Acknowledgements}

JAPC Decommissioning Project conducted this work. Dr. Kurosawa, Mr. Iida, Mr. Akatsu and Ms. Matsushita who are staff member of Toshiba Corporation performed 3D neutron flux distribution calculations by the contract. Nuclear Service Corporation performed radioactivity measurement in MS-tunnel Room and in S/C-Room of TS-1 by the contract.

\section{References}

[1] K. Tanaka, H. Ichige and H. Tanabe, Radiological characterization for small type light water reactor, Proc. ICONE19-2011, Oct. 24-25, 2011, Osaka, Japan, (2011), ISBN 9784888982047. [CD-ROM]

[2] ORNL, DOORS3.2: One, Two- and Three Dimensional Discrete Ordinates Neutron/Photon Transport Code System, CCC-650, Oak Ridge National Laboratory, (1998).

[3] K. Kosako, N. Yamano, T. Fukahori, K. Shibata and A. Hasegewa, The Libraries FSXLIB and MATXLIB Based on JENDL-3.3, JAERI-Data /Code 2003-011, Japan Atomic Energy Research Institute, (2003).

[4] SC-AESJ, Radiation Dose Conversion Coefficient for Radiation Shielding Calcylations:2010, AESJ-SC-R002:2010, Atomic Energy Society of Japan, (2010), ISBN 9784890473366.[in Japanese]

[5] I.C.Gauld, O.W. Hermann and R.M. Westfall, ORIGEN-S: SCALE System Module to Fuel Depletion, Actinide Transmutation, Fission Product Buildup and Decay Associated Radiation Source Terms, ORNL/TM-2005/39, Version 5.1, Vol. II, Book 1, Sect. F7, Oak Ridge National Laboratory, (2006).

[6] IAEA, Evaluating the Reliability of Predictions Made Using Environmental Transfer Models, Safety Series No.100, International Atomic Energy Agency, (1989), ISBN 9201240899. 